\title{
Progression of Cerebral Amyloid Load Is Associated with the Apolipoprotein E ع4 Genotype in Alzheimer's Disease
}

\author{
Timo Grimmer, Susanne Tholen, Behrooz H. Yousefi, Panagiotis Alexopoulos, Annette \\ Förschler, Hans Förstl, Gjermund Henriksen, William E. Klunk, Chester A. Mathis, Robert \\ Perneczky, Christian Sorg, Alexander Kurz, and Alexander Drzezga \\ Department of Psychiatry and Psychotherapy (TG, ST, PA, HF, RP, CS, AK); Department of \\ Nuclear Medicine (BHY, GH, AD); Department of Neuroradiology (AF), Klinikum rechts der Isar \\ der Technischen Universität München, Munich, Federal Republic of Germany; Department of \\ Psychiatry (WEK), Western Psychiatric Institute and Clinic; Department of Radiology (CAM), \\ University of Pittsburgh, Pittsburgh, Pennsylvania; and the Department of Radiology (AD), \\ Massachusetts General Hospital, Athinoula A. Martinos Center for Biomedical Imaging, Harvard \\ Medical School, Charlestown, Massachusetts
}

\section{Abstract}

Background-Pittsburgh Compound $\mathrm{B}\left(\left[{ }^{11} \mathrm{C}\right] \mathrm{PiB}\right)$ is a specific positron emission tomography (PET) marker of cerebral amyloid deposits. Only few data have been published on in vivo longitudinal changes of amyloid load in Alzheimer's disease (AD) patients, with conflicting results. Therefore, little is known about the factors that influence these changes.

\begin{abstract}
Methods-A group of 24 patients with probable AD diagnosed by combining established clinical criteria with an AD-typical pattern in $\left[{ }^{18} \mathrm{~F}\right]$ fluoro-deoxyglucose PET underwent $\left[{ }^{11} \mathrm{C}\right] \mathrm{PiB}-\mathrm{PET}$ examinations at baseline and after 24 months. The difference of amyloid load between the two examinations and the association with clinical and neurobiological variables was examined with a regions-of-interest approach and voxel-based analyses.
\end{abstract}

Results-Cerebral $\left[{ }^{11} \mathrm{C}\right] \mathrm{PiB}$ uptake ratio increased significantly by an annual rate of $3.92 \%$. Although the increase occurred in all parts of the neocortex, no increase was detected in the archipallium. The increase was gene-dose-dependent (analysis of variance $p=.012$ ) to the number of apolipoprotein E $\varepsilon 4$ alleles. Progression of dementia symptoms was correlated to the $\left[{ }^{11} \mathrm{C}\right] \mathrm{PiB}$ increase in numerous regions associated with cognition.

Conclusions-The results of this study indicate that a significant increase of amyloid deposition occurs in patients with $\mathrm{AD}$ during a relatively short interval of its clinical course. The rate of amyloid aggregation rate is closely associated with the apolipoprotein E genotype, which might be important for the evaluation of antiamyloid drug treatment effects. The present study further emphasizes the value of amyloid-plaque imaging as a marker of disease progression and as a potential surrogate marker to be used in antiamyloid drug trials.

\footnotetext{
Address correspondence to Timo Grimmer, M.D., Department of Psychiatry and Psychotherapy, Klinikum rechts der Isar, Technische Universität München, Möhlstrasse 26, 81675 Munich, Germany; t.grimmer@1rz.tum.de.

GE Healthcare (formerly Amersham Health, Chalfont St. Giles, UK) entered into a license agreement with the University of Pittsburgh on the basis of some of the technology described in this article. Dr. W.E. Klunk and Prof. C. A. Mathis are coinventors of [11 C] PiB and, as such, have a financial interest in this license agreement. The other authors reported no biomedical financial interests or potential conflicts of interest.

Supplementary material cited in this article is available online.
} 


\section{Keywords}

Alzheimer's disease; apolipoprotein E; Pittsburgh Compound B; positron emission tomography; prospective study

The characteristic histopathological features of Alzheimer's disease (AD) include senile plaques and neurofibrillary tangles in conjunction with loss of neurons and synapses $(1,2)$. The major constituent of senile plaques is amyloid $\beta$ protein $(A \beta)$. From cross-sectional histopathological studies it has been inferred that the cerebral amyloid load gradually increases during the preclinical and clinical course of $\operatorname{AD}(1,2)$. Topographically, it affects neocortical areas first, then spreads to allocortical areas such as gyrus cinguli and amygdala, later also involves diencephalic nuclei including thalamus and striatum, and finally extends to the brainstem and the cerebellum.

The apolipoprotein E (ApoE) genotype is the major genetic risk factor for sporadic AD. The presence of an ApoE $\varepsilon 4$ allele is associated with earlier symptom onset and a more rapid clinical decline $(3,4)$ as well as with greater hippocampal atrophy (5), hypoperfusion (6), hypometabolism (7), and $\left[{ }^{11} \mathrm{C}\right] \mathrm{PiB}$ uptake (8).

The radioligand $\left[{ }^{11} \mathrm{C}\right] \mathrm{PiB}$ (Pittsburgh Compound $\mathrm{B}$ ) binds to different kinds of cerebral $\mathrm{A} \beta$ including plaque, nonplaque, and vessel wall deposits, but has minimal affinity to other types of protein aggregations, such as neurofibrillary tangles or Lewy bodies (9-12). As a research tool, the tracer is available for the imaging of cerebral amyloid plaques with positron emission tomography (PET) (13) and makes it possible to study the progression of cerebral amyloid deposition in vivo. This might provide valuable insight how amyloid deposition is associated with the progression of clinical symptoms and could help identify factors that enhance or attenuate amyloid deposition. Previous prospective studies that looked at the evolution of amyloid load in $\mathrm{AD}$ with serial $\left[{ }^{11} \mathrm{C}\right] \mathrm{PiB}$ scans have yielded controversial results. In one study, rescanning of 16 patients with mild $\mathrm{AD}$ at an average interval of $23.9 \pm 5.6$ months showed no significant change in $\left[{ }^{11} \mathrm{C}\right] \mathrm{PiB}$ retention in regions of interest (ROI) that were not precisely aligned to anatomic boundaries (14). A second study on 14 individuals with very mild to moderate $\mathrm{AD}$ demonstrated an increase in $\left[{ }^{11} \mathrm{C}\right]$ $\mathrm{PiB}$ uptake relative to baseline after $24.2 \pm 2.4$ months in most patients but a decrease of tracer uptake in a minority of subjects (15). In a third study that involved eight patients with very mild to mild $\mathrm{AD}$ who were reexamined at an average interval of 12 months, a nonsignificant increase of $\left[{ }^{11} \mathrm{C}\right] \mathrm{PiB}$ uptake was observed (16).

The aims of the current study were to: 1) determine the progression of $\left[{ }^{11} \mathrm{C}\right] \mathrm{PiB}$ uptake in clinically well-characterized $\mathrm{AD}$ patients with initially very mild to moderate dementia within a follow-up period of 24 months; 2) examine whether there are differences among brain topographic regions with regard to the rate of progression; 3 ) identify clinical or neurobiological variables that are associated with the progression of amyloid deposition; and 4) investigate the relationship between the increase of $\left[{ }^{11} \mathrm{C}\right] \mathrm{PiB}$ uptake and clinical deterioration.

\section{Methods and Materials}

\section{Patient Recruitment, Inclusion, and Exclusion Criteria}

Patients were recruited from the research outpatient unit for cognitive disorders at the Department of Psychiatry, Klinikum rechts der Isar, Technische Universitaet, Muenchen, Munich, Germany. They had been referred for the diagnostic evaluation of cognitive 
impairment by general practitioners, neurologists, psychiatrists, or other institutions and had undergone a standardized diagnostic procedure.

The diagnostic work-up included an interview with the patient and an informant; medical, psychiatric, and neurological examinations; neuropsychological evaluation including the Mini Mental State Examination (MMSE) (17) and the Consortium to Establish a Registry for Alzheimer's disease Neuropsychological Assessment Battery (CERAD-NAB) (18), a routine laboratory screen, and ApoE genotyping. The severity of cognitive impairment was rated on the Clinical Dementia Rating scale (CDR) (19). Cranial magnetic resonance imaging (MRI) was performed to assess structural brain abnormalities. In addition, in study participants, cranial $\left[{ }^{18} \mathrm{~F}\right]$ fluoro-deoxyglucose positron emission tomography (FDG-PET) was used to measure cerebral metabolism, and $\left[{ }^{11} \mathrm{C}\right] \mathrm{PiB}$-PET was used to assess brain amyloid burden.

The study protocol was approved by the ethics committee of the medical faculty and by radiation protection authorities. All patients provided written informed consent before any study-specific procedure. Informed consent was reobtained before the follow-up examination.

All study participants met National Institute of Neurological and Communicative Disorders and Stroke-Alzheimer's Disease and Related Disorders Association diagnostic criteria for Probable Alzheimer's disease (20). Patients with very mild to moderate dementia as defined by global CDR ratings of $.5,1$, or 2 were included. Furthermore, to enhance the likelihood of underlying $\mathrm{AD}$ pathology $\left[{ }^{18} \mathrm{~F}\right]$ FDG-PET findings typical for $\mathrm{AD}$ were required for inclusion $(21,22)$ (i.e., hypometabolism in the temporo-parietal and posterior cingulate cortex with relative sparing of the primary sensomotor cortex on visual inspection) (23).

Patients were not included in the study if they met diagnostic criteria for other neurological or psychiatric disorders, including Parkinson's disease, normal pressure hydrocephalus, progressive nuclear palsy, or major depression. Patients were also excluded if they showed any major abnormalities on MRI, such as brain infarcts, extensive leukoencephalopathy, intracerebral aneurysm, or arteriovenous malformation. Moreover, patients showing $\left[{ }^{18} \mathrm{~F}\right]$ FDG-PET findings that are atypical of AD were excluded. National Institute of Neurological Disorders and Stroke and the Association Internationale pour la Recherche et l'Enseignement en Neurosciences criteria were used to exclude vascular dementia (24). Furthermore, patients with other possible causes of cognitive impairment such as psychotropic medication (e.g., antidepressants, antipsychotics), substance misuse, or major abnormalities in routine blood testing were not enrolled. The $\left[{ }^{11} \mathrm{C}\right]$ PiB-PET findings were not used as inclusion criteria.

Patients who did not participate in the follow-up examination for any reason were also excluded from the analyses.

\section{Laboratory Screen and ApoE Genotyping}

Routine blood screening included a standard serologic chemistry group, full blood cell count, blood glucose, vitamin B12 and folic acid levels, thyroid hormone levels, as well as serologic tests for syphilis and Lyme borreliosis. The ApoE genotype was determined after a standardized protocol with a PCR-based essay that simultaneously uses two distinct restriction enzymes (25).

\section{Brain Imaging}

Structural MRI, $\left[{ }^{18} \mathrm{~F}\right]$ FDG-PET, and $\left[{ }^{11} \mathrm{C}\right]$ PiB-PET of the brain were obtained at baseline and at follow-up examinations with standard procedures $(26,27)$. The $\left[{ }^{11} \mathrm{C}\right] \mathrm{PiB}$ images were 
coregistered to high-resolution MRI scans and normalized to the Montreal Neurological Institute space with the warping parameters of the MRI to obtain interindividually comparable images. Follow-up visits including CERAD-NAB, CDR, MRI, and $\left[{ }^{11} \mathrm{C}\right] \mathrm{PiB}$ examinations were scheduled 24 months after the baseline assessment.

\section{Statistical Analysis}

A relative measure of $\left[{ }^{11} \mathrm{C}\right] \mathrm{PiB}$ uptake was obtained by calculating a cerebral to cerebellar vermis $(\mathrm{C} / \mathrm{cv})$ ratio for each patient to control for between-subjects differences in tracer uptake as demonstrated previously (26). For this purpose, two anatomical ROIs were defined, one covering the entire cerebral gray matter, the other the cerebellar vermis as a reference region, with an established predefined template (28). Mean standard uptake volume values were calculated for the $95 \%$ of voxels that showed the highest uptake values for each ROI (29). To determine the progression of $\left[{ }^{11} \mathrm{C}\right] \mathrm{PiB}$ uptake, the difference between the $\mathrm{C} / \mathrm{cv}\left[{ }^{11} \mathrm{C}\right] \mathrm{PiB}$ uptake ratios at baseline and at follow-up was calculated with a Wilcoxon test.

To examine whether there are differences among brain topographic regions with regard to rate of $\left[{ }^{11} \mathrm{C}\right] \mathrm{PiB}$ uptake progression, the cerebrum was divided into 90 anatomically defined ROIs with the aforementioned template, and ROIs to cerebellar vermis ratios were calculated, accordingly. The differences between the $\left[{ }^{11} \mathrm{C}\right] \mathrm{PiB}$ uptake ratios in these ROIs at baseline and at follow-up were calculated with Wilcoxon tests, not controlling for multiple comparisons. To control for possible false positive results, we post hoc combined phylogenetic comparable regions resulting in two ROIs, one covering the archipallium and the other the neocortex.

To identify clinical or neurobiological variables that are associated with the progression of amyloid deposition, regression analyses were used. The difference of the $\mathrm{C} / \mathrm{cv}\left[{ }^{11} \mathrm{C}\right] \mathrm{PiB}$ uptake ratio between baseline and follow-up examination in the cerebral areas where an increase occurred was used as dependent variable; and gender, age, ApoE $\varepsilon 4$ genotype, between-scan interval, baseline $\left[{ }^{11} \mathrm{C}\right] \mathrm{PiB}$ uptake ratio, and global $\mathrm{CDR}$ at baseline were used as independent variables. In addition, for variables identified as associated with the progression of amyloid deposition, subgroup analyses were carried out.

To investigate the association between the increase of $\left[{ }^{11} \mathrm{C}\right] \mathrm{PiB}$ and clinical deterioration, voxel-based regression analyses were performed between $\left[{ }^{11} \mathrm{C}\right] \mathrm{PiB}$ increase and differences in the CDR sum of boxes (CDR SOB), MMSE, and CERAD-NAB total score (30) from baseline to follow-up, respectively, with statistical parametric mapping version 8 (SPM8) (31). As a preprocessing method for these analyses, the individual spatially normalized $\left[{ }^{11} \mathrm{C}\right]$ $\mathrm{PiB}$ images were quantitatively normalized to the cerebellar vermis and smoothed (Gaussian kernel of $10 \times 10 \times 10 \mathrm{~mm}$ ), and individual subtraction images of baseline to follow-up were generated. For the voxel-based regression analyses, a significance threshold of .01 uncorrected was applied as in previous studies (27).

\section{Results \\ Patients}

Informed consent was obtained from 42 patients. Of these, 18 did not participate in the follow-up examination and were excluded from the analysis. Four patients had died, five patients had become too ill to undergo PET or MRI examinations, and nine patients or their caregivers had withdrawn consent. The remaining 24 patients were included in the present study. The demographic data of the sample are provided in Table 1. All patients fulfilled diagnostic criteria of probable AD. Three patients who showed no impairment on the MMSE (28-30 points) exhibited cognitive deficits in neuropsychological testing; all three 
showed deficits in verbal memory, two had constructional apraxia, and two had deficits in executive functions. Nine patients did not carry the ApoE $\varepsilon 4$ allele, 10 patients carried one, and five patients carried two alleles. All patients showed a pattern of hypometabolic areas on $\left[{ }^{18} \mathrm{~F}\right]$ FDG-PET that was consistent with the diagnosis of AD. The 24 patients were reexamined after a mean interval of $26.6 \pm 2.56$ months (range 22-32 months). All assessments (neuropsychological testing, MRI, PET) were performed at baseline within $26 \pm$ 21 days and at follow-up within $13 \pm 23$ days with a maximum of 80 days.

\section{Clinical Deterioration}

Within this time interval, the clinical decline was 4.8 $\pm 5.91 \mathrm{U}$ on the MMSE (Wilcoxon $p$ $=.002), 11.3 \pm 13.26 \mathrm{U}$ on the CERAD-NAB total score $(p=.001)$, and $3.13 \pm 2.99 \mathrm{U}$ on the CDR SOB $(p<.001)$ (Table 2$)$.

\section{Progression of $\left[{ }^{11} \mathrm{C}\right] \mathrm{PiB}$ Uptake}

The mean $\mathrm{C} / \mathrm{cv}\left[{ }^{11} \mathrm{C}\right] \mathrm{PiB}$ uptake ratio was $1.68 \pm .32$ at baseline and $1.82 \pm .35$ at followup. The difference was statistically significant $(p=.001)$.

It corresponds to a rate of change relative to baseline of $8.7 \% \pm 14.3 \%$ (mean annual rate of change: $3.92 \%$ ), which was also significant. The cerebellar vermis that was used as the reference region did not show a significant change of $\left[{ }^{11} \mathrm{C}\right] \mathrm{PiB}$ uptake between baseline and follow-up examinations.

\section{Topographic Differences in the Rate of Progression}

The comparison of the relative tracer uptake in the 90 ROIs revealed that the progression of amyloid deposition shows topographic differences. There were relatively low baseline $\left[{ }^{11} \mathrm{C}\right]$ $\mathrm{PiB}$ uptake ratios and no increase from baseline to follow-up in the archipallium, thalami, and the nuclei caudati. Relatively high baseline $\left[{ }^{11} \mathrm{C}\right] \mathrm{PiB}$ uptake ratios and an increase between the two measurements were observed in almost all neocortical ROIs. In the neocortex the increase of $\left[{ }^{11} \mathrm{C}\right] \mathrm{PiB}$ uptake tended to be highest in frontal ROIs, to a lesser extent in parietal and occipital ROIs, and lowest in temporal ROIs. The mean $\left[{ }^{11} \mathrm{C}\right] \mathrm{PiB}$ uptake in the ROIs at baseline and follow-up and the difference between the two assessments are shown in Table S1 in Supplement 1. In the ROI that covers the whole archipallium, $\left[{ }^{11} \mathrm{C}\right] \mathrm{PiB}$ uptake did not increase between baseline and follow-up (difference of $\left[{ }^{11} \mathrm{C}\right] \mathrm{PiB}$ uptake ratio $-.020 \pm .0650$, Wilcoxon $\left.p=0,241\right)$, whereas in the ROI that covers the neocortex there was a significant increase between the two assessments (difference of $\left[{ }^{11} \mathrm{C}\right] \mathrm{PiB}$ uptake ratio $+.144 \pm .1820$, Wilcoxon $p=0,001$ ). These post hoc analyses confirmed the observations in the aforementioned ROI analyses.

\section{Associated Clinical or Neurobiological Variables}

The regression analyses between the difference of $\left[{ }^{11} \mathrm{C}\right] \mathrm{PiB}$ uptake ratios in the cerebrum between baseline and follow-up as dependent variable and gender, between-scan interval, baseline $\left[{ }^{11} \mathrm{C}\right] \mathrm{PiB}$ uptake ratio, and $\mathrm{CDR}$ global at baseline resulted in negative values for corrected $R^{2}$, indicating that these variables did not explain any variability of the increase. Age showed a nonsignificant corrected $R^{2}$ of .016 . Of all clinical variables, only the ApoE $\varepsilon 4$ genotype was significantly associated ( $p$ value .034$)$ with the change in relative $\left[{ }^{11} \mathrm{C}\right] \mathrm{PiB}$ tracer uptake. The regression coefficient $\beta$ was .435. The corrected $R^{2}$ value of .152 indicates that $15.2 \%$ of the variability of the difference between baseline and follow-up $\left[{ }^{11} \mathrm{C}\right] \mathrm{PiB}$ uptake is predicted by the number of ApoE $\varepsilon 4$ alleles.

Subgroup analyses stratifying for the number of ApoE $\varepsilon 4$ alleles showed that the increase in $\mathrm{C} / \mathrm{cv}\left[{ }^{11} \mathrm{C}\right] \mathrm{PiB}$ uptake ratio was significantly associated with the ApoE $\varepsilon 4$ gene dose. The mean increase of relative $\left[{ }^{11} \mathrm{C}\right] \mathrm{PiB}$ uptake for zero, one, and two alleles was $.05, .17$, and 
31 (analysis of variance $p=.012$ ), and the mean rate of change was 3\%,10\%, and 22\%

(analysis of variance $p=.035$ ), respectively. The statistical analyses are shown in Table 3 .

\section{Relationship Between the $\left[{ }^{11} \mathrm{C}\right] \mathrm{PiB}$ Uptake Progression and Clinical Decline}

The voxel-based regression analysis between change in $\left[{ }^{11} \mathrm{C}\right] \mathrm{PiB}$ uptake and change of CDR SOB showed significant associations in the right frontal lobe, the left inferior frontal gyrus, the temporal lobes of both sides, the right cuneus/precuneus/posterior cingulated area, the parahippocampal gyrus of both sides, and in the cerebellum area. Surface projections of the areas of significant differences are displayed in Figure 1. Maximal and anatomical correlations of the clusters of significant differences are provided in Table S2 in Supplement 1. Two exemplary scatterplots of significant associations in the right precuneus and the left parahippocampal gyrus are displayed in Figure S1 in Supplement 1. The analysis between $\left[{ }^{11} \mathrm{C}\right] \mathrm{PiB}$ difference and differences of MMST revealed a widespread pattern of significant associations including frontal and temporal lobes of both sides. Surface projections of the areas of significant differences are displayed in Figure 2. Maximal and anatomical correlations of the clusters of significant differences are given in Table S3 in Supplement 1. The analysis between $\left[{ }^{11} \mathrm{C}\right] \mathrm{PiB}$ increase and differences of CERAD-NAB total showed no significant associations.

\section{Discussion}

In the current study we analyzed the change of $\mathrm{C} / \mathrm{cv}\left[{ }^{11} \mathrm{C}\right] \mathrm{PiB}$ uptake ratios during a mean interval of 26.6 months in a sample of 24 patients with $\mathrm{AD}$ who were diagnosed clinically and with $\left[{ }^{18} \mathrm{~F}\right]$ FDG-PET. The $\left[{ }^{11} \mathrm{C}\right] \mathrm{PiB}$ uptake, which is an in vivo marker of cerebral amyloid deposition, showed a statistically significant increase within this relatively short time interval.

Tracer uptake at baseline and increased uptake at follow-up was most prominent in the neocortex, whereas relatively low baseline and no increase were observed in the archipallium, the nuclei caudati and the thalami. A sequence of $A \beta$ deposition has been hypothesized, on the basis of histopathological observations, asserting that neocortical areas are firstly affected, followed by the archipallium, and finally by diencephalic nuclei (2). According to this histopathological model the patient sample of the present study represents initial stages of amyloid deposition.

The mean increase of the $\mathrm{C} / \mathrm{cv}\left[{ }^{11} \mathrm{C}\right] \mathrm{PiB}$ uptake ratio was .062/year, which equates to an annual rate of change of $+3.92 \%$ with large interindividual differences. Because no partial volume correction was performed to control for the progressive cortical atrophy, the increase of the $\left[{ }^{11} \mathrm{C}\right] \mathrm{PiB}$ uptake ratios might even be underestimated. The total rate of change of $8.7 \%$ at mean is greater than the reported test-retest variability of this method with a reference tissue model $(32,33)$ and therefore probably indicates a real change.

The observed increase of $\left[{ }^{11} \mathrm{C}\right] \mathrm{PiB}$ uptake is comparable to the observations in one study showing a nonsignificant mean increase of .06/year (16) but is at variance with the results of two other studies $(14,15)$ that did not demonstrate a significant increase of $\left[{ }^{11} \mathrm{C}\right] \mathrm{PiB}$ uptake after a 2-year follow-up. The heterogeneity of findings might be due to a number of factors. First, the sample size of the present study, although still rather limited, was 1.5-3-fold larger than in previous studies (14-16). Given the large interindividual differences of increase of relative tracer uptake, the increase might have been missed in smaller patient cohorts. Second, the careful selection of patients including $\left[{ }^{18} \mathrm{~F}\right]$ FDG PET for inclusion might have enhanced the proportion of patients with underlying AD pathology and study power $(21,22)$. Third, assuming that dynamics of tracer uptake are not completely homogeneous across different brain regions, differences in the selection of the boundaries of the ROIs might have 
an impact on results (14). Fourth, the average between-scan interval was 26 months in the present study, which was longer than in a previous investigation (16). Finally, different ApoE allele frequencies in the patient samples (16) might have influenced the findings.

The relationship between the increase of $\left[{ }^{11} \mathrm{C}\right] \mathrm{PiB}$ uptake ratio and the ApoE genotype suggests a gene-dose effect. Each additional $\varepsilon 4$ allele was associated with an increase of tracer uptake at baseline and of tracer uptake increment over 2 years. This observation is consistent with the well-established findings that $\mathrm{ApoE} \varepsilon 4$ carriers show more rapid decline of clinical symptoms $(3,4)$, accelerated hippocampal atrophy $(5)$, as well as greater amounts and faster progression of deficits in cerebral blood flow (6) and metabolism (7).

One strength of the present study is that patients with a wide spectrum of dementia from very mild to moderate were included. Severely impaired patients already at baseline were excluded, because they were unlikely to complete the follow-up examination.

There is a lack of association between the increase of $\left[{ }^{11} \mathrm{C}\right] \mathrm{PiB}$ uptake and baseline clinical severity and between the increase of $\left[{ }^{11} \mathrm{C}\right] \mathrm{PiB}$ uptake and baseline $\left[{ }^{11} \mathrm{C}\right] \mathrm{PiB}$ uptake. Therefore, the increase in $\left[{ }^{11} \mathrm{C}\right] \mathrm{PiB}$ uptake was no less in more advanced patients.

The variable age resulted in a nonsignificant, small, positive corrected $R^{2}$ in the regression analysis with the increase of $\left[{ }^{11} \mathrm{C}\right] \mathrm{PiB}$ uptake. Thus, age of patients might turn out to be significantly associated with the rate of $\left[{ }^{11} \mathrm{C}\right] \mathrm{PiB}$ increase in a larger sample.

With a voxel-based approach, significant associations between difference of $\left[{ }^{11} \mathrm{C}\right] \mathrm{PiB}$ uptake and CDR SOB as well as MMSE were demonstrated in several brain regions, many of which can be associated with cognition, particularly with different memory functions (34-36). Although these results indicate that $\left[{ }^{11} \mathrm{C}\right] \mathrm{PiB}$ uptake correlates only in certain brain regions with clinical symptoms, this location-dependency might explain the moderate association of whole brain amyloid load and clinical severity in cross-sectional histopathological $(37,38)$ and $\left[{ }^{11} \mathrm{C}\right] \mathrm{PiB}(26)$ studies. However, the strength of this association might be underestimated, because the small decline of the clinical variables reduces variability and because the initiation of symptomatic drug treatment between study assessments might have attenuated clinical deterioration.

The present study has several limitations. First, the clinical diagnosis of AD was not confirmed by postmortem examination, and misclassification of patients as AD might have influenced the strength of the association. However, patients were only enrolled if they showed AD-typical findings on $\left[{ }^{18} \mathrm{~F}\right]$ FDG-PET. Second, the sample size was relatively small. A study in a larger patient sample would be of great interest to determine whether there are further variables associated with $\left[{ }^{11} \mathrm{C}\right] \mathrm{PiB}$ increase.

In conclusion, we found a significant $\left[{ }^{11} \mathrm{C}\right] \mathrm{PiB}$ increase after a mean of 26.6 months of follow-up with an annual rate of change of $+3.92 \%$ with large interindividual difference. This emphasizes the value of $\left[{ }^{11} \mathrm{C}\right] \mathrm{PiB}$ as a marker of disease progression and as a potential surrogate marker for antiamyloid drug trials. The increase in $\left[{ }^{11} \mathrm{C}\right] \mathrm{PiB}$ uptake was modified by the ApoE $\varepsilon 4$ genotype in a gene-dose-dependent manner. This observation could be of interest for the dosing and effectiveness of future antiamyloid treatment strategies. The association with clinical symptoms was location-dependent, which might explain the moderate associations between whole brain amyloid and disease severity as found in previous studies.

\section{Supplementary Material}

Refer to Web version on PubMed Central for supplementary material. 


\section{Acknowledgments}

This work was supported in part by the German research foundation (Deutsche Forschungsgemeinschaft) (HE 4560/1-2 to GH, AD, and HJW, DR 445/3-1 to AD, GH, and AK, DR 445/4-1 to AD, GH, AK); by a KKF-grant for clinical research of the Technische Universität München (to AD and TG); and by the National Institutes of Health (R01 AG018402 to CAM, R37 AG025516 to WEK, P01 AG025204 to WEK).

We would like to thank Dr. Victoria Kehl from the Department of Statistics and Epidemiology for her statistical advice.

\section{References}

1. Braak H, Braak E. Neuropathological staging of Alzheimer-related changes. Acta Neuropathol 1991;82:239-259. [PubMed: 1759558]

2. Thal DR, Rüb U, Orantes M, Braak H. Phases of A $\beta$-deposition in the human brain and its relevance for the development of AD. Neurology 2002;58:1791-1800. [PubMed: 12084879]

3. Cosentino S, Scarmeas N, Helzner E, Glymour MM, Brandt J, Albert M, et al. APOE epsilon 4 allele predicts faster cognitive decline in mild Alzheimer disease. Neurology 2008;70:1842-1849. [PubMed: 18401023]

4. Craft S, Teri L, Edland SD, Kukull WA, Schellenberg G, McCormick WC, et al. Accelerated decline in apolipoprotein E-epsilon4 homozygotes with Alzheimer's disease. Neurology 1998;51:149-153. [PubMed: 9674794]

5. Mori E, Lee K, Yasuda M, Hashimoto M, Kazui H, Hirono N, Matsui M. Accelerated hippocampal atrophy in Alzheimer's disease with apolipoprotein E epsilon4 allele. Ann Neurol 2002;51:209_ 214. [PubMed: 11835377]

6. Lehtovirta M, Kuikka J, Helisalmi S, Hartikainen P, Mannermaa A, Ryynanen M, et al. Longitudinal SPECT study in Alzheimer's disease: Relation to apolipoprotein E polymorphism. J Neurol Neurosurg Psychiatry 1998;64:742-746. [PubMed: 9647302]

7. Drzezga A, Riemenschneider M, Strassner B, Grimmer T, Peller M, Knoll A, et al. Cerebral glucose metabolism in patients with AD and different APOE genotypes. Neurology 2005;64:102-107. [PubMed: 15642911]

8. Drzezga A, Grimmer T, Henriksen G, Muhlau M, Perneczky R, Miederer I, et al. Effect of APOE genotype on amyloid plaque load and gray matter volume in Alzheimer disease. Neurology 2009;72:1487-1494. [PubMed: 19339712]

9. Ikonomovic MD, Klunk WE, Abrahamson EE, Mathis CA, Price JC, Tsopelas ND, et al. Postmortem correlates of in vivo PiB-PET amyloid imaging in a typical case of Alzheimer's disease. Brain 2008;131:1630-1645. [PubMed: 18339640]

10. Lockhart A, Lamb JR, Osredkar T, Sue LI, Joyce JN, Ye L, et al. PIB is a non-specific imaging marker of amyloid-beta (A $\beta$ ) peptide-related cerebral amyloidosis. Brain 2007;130:2607-2615. [PubMed: 17698496]

11. Fodero-Tavoletti MT, Smith DP, McLean CA, Adlard PA, Barnham KJ, Forster LE, et al. In vitro characterization of Pittsburgh compound-B binding to Lewy bodies. J Neurosci 2007;27:1036510371. [PubMed: 17898208]

12. Ye L, Velasco A, Fraser G, Beach TG, Sue L, Osredkar T, et al. In vitro high affinity alphasynuclein binding sites for the amyloid imaging agent PIB are not matched by binding to Lewy bodies in postmortem human brain. J Neurochem 2008;105:1428-1437. [PubMed: 18221373]

13. Klunk WE, Engler H, Nordberg A, Wang Y, Blomqvist G, Holt DP, et al. Imaging brain amyloid in Alzheimer's disease with Pittsburgh compound-B. Ann Neurol 2004;55:306-319. [PubMed: 14991808]

14. Engler H, Forsberg A, Almkvist O, Blomquist G, Larsson E, Savitcheva I, et al. Two-year followup of amyloid deposition in patients with Alzheimer's disease. Brain 2006;129:2856-2866. [PubMed: 16854944]

15. Scheinin NM, Aalto S, Koikkalainen J, Lotjonen J, Karrasch M, Kemppainen N, et al. Follow-up of [11C]PIB uptake and brain volume in patients with Alzheimer disease and controls. Neurology 2009;73:1186-1192. [PubMed: 19726751] 
16. Jack CR Jr, Lowe VJ, Weigand SD, Wiste HJ, Senjem ML, Knopman DS, et al. Serial PIB and MRI in normal, mild cognitive impairment and Alzheimer's disease: Implications for sequence of pathological events in Alzheimer's disease. Brain 2009;132:1355-1365. [PubMed: 19339253]

17. Folstein MF, Folstein SE, McHugh PR. "Mini Mental State." A practical method for grading the cognitive state of patients for the clinician. J Psychiatr Res 1975;12:189-198. [PubMed: 1202204]

18. Berres M, Monsch AU, Bernasconi F, Thalmann B, Stahelin HB. Normal ranges of neuropsychological tests for the diagnosis of Alzheimer's disease. Stud Health Technol Inform 2000;77:195-199. [PubMed: 11187541]

19. Morris JC, Heyman A, Mohs RC, Hughes JP, van Belle G, Fillenbaum G, et al. The Consortium to Establish a Registry for Alzheimer's disease (CERAD). Part I. Clinical and neuropsychological assessment of Alzheimer's disease. Neurology 1989;39:1159-1165. [PubMed: 2771064]

20. McKhann G, Drachman D, Folstein M, Katzman R, Price D, Stadlan EM. Clinical diagnosis of Alzheimer's disease: Report of the NINCDS-ADRDA Work Group under the auspices of Department of Health and Human Services Task Force on Alzheimer's Disease. Neurology 1984;34:939-944. [PubMed: 6610841]

21. Hoffman JM, Welsh-Bohmer KA, Hanson M, Crain B, Hulette C, Earl N, Coleman RE. FDG PET imaging in patients with pathologically verified dementia. J Nucl Med 2000;41:1920-1928. [PubMed: 11079505]

22. Jagust W, Reed B, Mungas D, Ellis W, Decarli C. What does fluoro-deoxyglucose PET imaging add to a clinical diagnosis of dementia? Neurology 2007;69:871-877. [PubMed: 17724289]

23. Minoshima S. Imaging Alzheimer's disease: Clinical applications. Neuroimaging Clin N Am 2003;13:769-780. [PubMed: 15024960]

24. Roman GC, Tatemichi TK, Erkinjuntti T, Cummings JL, Masdeu JC, Garcia JH, et al. Vascular dementia: Diagnostic criteria for research studies. Report of the NINDS-AIREN International workshop. Neurology 1993;43:250-260. [PubMed: 8094895]

25. Zivelin A, Rosenberg N, Peretz H, Amit Y, Kornbrot N, Seligsohn U. Improved method for genotyping apolipoprotein E polymorphisms by a PCR-based assay simultaneously utilizing two distinct restriction enzymes. Clin Chem 1997;43:1657-1659. [PubMed: 9299950]

26. Grimmer T, Henriksen G, Wester HJ, Forstl H, Klunk WE, Mathis CA, et al. Clinical severity of Alzheimer's disease is associated with PIB uptake in PET. Neurobiol Aging 2009;30:1902-1909. [PubMed: 18346821]

27. Grimmer T, Riemenschneider M, Forstl H, Henriksen G, Klunk WE, Mathis CA, et al. Beta amyloid in Alzheimer's disease: Increased deposition in brain is reflected in reduced concentration in cerebrospinal fluid. Biol Psychiatry 2009;65:927-934. [PubMed: 19268916]

28. Tzourio-Mazoyer N, Landeau B, Papathanassiou D, Crivello F, Etard O, Delcroix N, et al. Automated anatomical labeling of activations in SPM using a macroscopic anatomical parcellation of the MNI MRI single-subject brain. Neuroimage 2002;15:273-289. [PubMed: 11771995]

29. Loening AM, Gambhir SS. AMIDE: A free software tool for multimodality medical image analysis. Mol Imaging 2003;2:131-137. [PubMed: 14649056]

30. Chandler MJ, Lachritz LH, Bernard HD, Allen G, Deschner M, Weiner MF, et al. A total score for the CERAD neuropsychological battery. Neurology 2005;65:102-106. [PubMed: 16009893]

31. Friston KJ, Holmes AP, Worsley KJ. Statistical parametric mapping in functional imaging: A general linear approach. Hum Brain Mapp 1995;2:189-210.

32. Aalto S, Scheinin NM, Kemppainen NM, Nagren K, Kailajarvi M, Leinonen M, et al. Reproducibility of automated simplified voxel-based analysis of PET amyloid ligand [11C]PIB uptake using 30-min scanning data. Eur J Nucl Med Mol Imaging 2009;36:1651-1660. [PubMed: 19495749]

33. Tolboom N, Yaqub M, Boellaard R, Luurtsema G, Windhorst AD, Scheltens P, et al. Test-retest variability of quantitative [11C]PIB studies in Alzheimer's disease. Eur J Nucl Med Mol Imaging 2009;36:1629-1638. [PubMed: 19384547]

34. Cabeza R, Nyberg L. Imaging cognition. II: An empirical review of 275 PET and fMRI studies. J Cogn Neurosci 2000;12:1-47. [PubMed: 10769304] 
35. Moscovitch M, Rosenbaum RS, Gilboa A, Addis DR, Westmacott R, Grady C, et al. Functional neuroanatomy of remote episodic, semantic and spatial memory: A unified account based on multiple trace theory. J Anat 2005;207:35-66. [PubMed: 16011544]

36. Schlosser RG, Wagner G, Sauer H. Assessing the working memory network: Studies with functional magnetic resonance imaging and structural equation modeling. Neuroscience 2006;139:91-103. [PubMed: 16324797]

37. Gold G, Kövari E, Corte G, Herrmann F, Canuto A, Bussiere T, et al. Clinical validity of A $\beta$ protein deposition staging in brain aging and Alzheimer disease. J Neuropathol Exp Neurol 2001;60:946-952. [PubMed: 11589425]

38. McKeel DW, Price JL, Miller JP, Grant EA, Xiong C, Berg L, Morris JC. Neuropathologic criteria for diagnosing Alzheimer disease in persons with pure dementia of Alzheimer type. J Neuropathol Exp Neurol 2004;63:1028-1037. [PubMed: 15535130] 


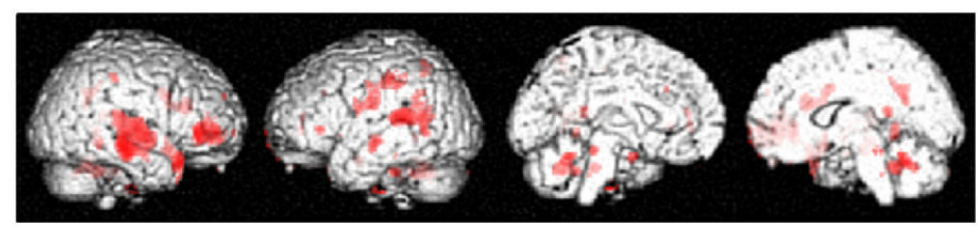

Figure 1.

Voxel-based regression analysis between Pitts-burgh Compound B $\left(\left[{ }^{11} \mathrm{C}\right] \mathrm{PiB}\right)$ difference and clinical dementia rating sum of boxes difference. Significant $(<.01)$ correlations are depicted in red and are projected on a rendered magnetic resonance image, projection: right lateral, left lateral, left mesial, right mesial $\left[{ }^{11} \mathrm{C}\right]$. 


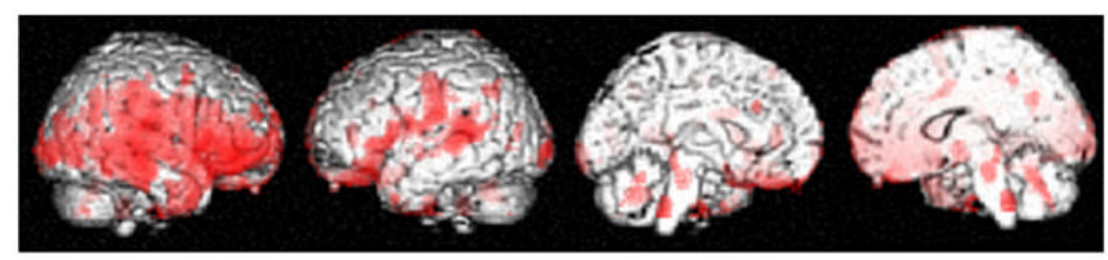

Figure 2.

Voxel-based regression analysis between Pitts-burgh Compound B $\left(\left[{ }^{11} \mathrm{C}\right] \mathrm{PiB}\right)$ difference and mini mental state examination difference. Significant $(<.01)$ correlations are depicted in red and are projected on a rendered magnetic resonance image, projection: right lateral, left lateral, left mesial, right mesial, $\left[{ }^{11} \mathrm{C}\right]$. 


\section{Table 1}

Demographic Data

\begin{tabular}{lc}
\hline Number & 24 \\
Male:Female & $15: 9$ \\
Age in Yrs at Baseline, mean/SD/range & $66.1 / 7.22 / 52-77$ \\
Patients on Cholinesterase Inhibitors/Memantine & Baseline: 6/0 \\
& Follow-Up: 18/2 \\
\hline
\end{tabular}




\section{Table 2}

Clinical Characteristics

\begin{tabular}{ll}
\hline & Mean/SD/Range \\
\hline MMSE at Baseline & $23.8 / 3.94 / 15-30$ \\
MMSE at Follow-Up & $19.0 / 9.24 / 0-30$ \\
CDR SOB at Baseline & $3.75 / 1.978 / 0.5-9$ \\
CDR SOB at Follow-Up & $6.88 / 3.995 / 2.0-16.0$ \\
CERAD-NAB Total at Baseline & $57.2 / 14.64 / 31-82$ \\
CERAD-NAB Total at Follow-Up & $45.4 / 20.52 / 16-82$ \\
\hline
\end{tabular}

MMSE, Mini Mental State Examination; CDR SOB, clinical dementia rating sum of boxes; CERAD-NAB, Neuropsychological Test Battery of Consortium to Establish a Registry for Alzheimer's Disease. 
Table 3

$\left[{ }^{11} \mathrm{C}\right]$ PiB Ratios Stratified by ApoE-Genotype

\begin{tabular}{lccc}
\hline ApoE $\boldsymbol{\varepsilon}$ 4-Allele & $\mathbf{0}$ & $\mathbf{1}$ & $\mathbf{2}$ \\
\hline$n$ & 9 & 10 & 5 \\
Baseline: mean/SD & $1.51 / 0.226$ & $1.70 / 0.299$ & $1.79 / 0.373$ \\
Follow-Up: mean/SD & $1.57 / 0.280$ & $1.87 / 0.371$ & $2.09 / 0.111$ \\
Difference: mean/SD & $0.05 / 0.115$ & $0.17 / 0.122$ & $0.31 / 0.273$ \\
Rate of Change: mean/SD & $3 \% / 7.7 \%$ & $10 \% / 7.8 \%$ & $22 \% / 27.1 \%$ \\
$p$ value (Wilcoxon) & .327 & .015 & .043 \\
\hline
\end{tabular}

$\left[{ }^{11} \mathrm{C}\right] \mathrm{PiB}$, Pittsburgh Compound B; ApoE, apolipoprotein E. 